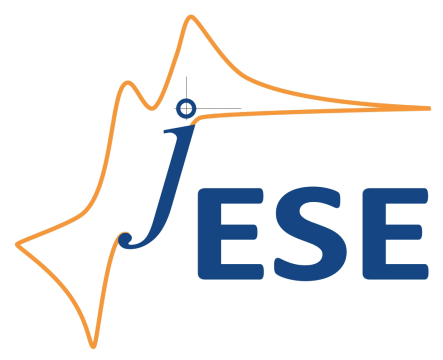

Open Access : : ISSN 1847-9286

www.jESE-online.org

Original scientific paper

\title{
Corrosion inhibition of carbon steel by extract of Buddleia perfoliata
}

\author{
ROY LOPES-SESENES, JOSE GONZALO GONZALEZ-RODRIGUEZ ${ }^{\bowtie}$, GLORIA FRANCISCA \\ DOMINGUEZ-PATIÑO*, ALBERTO MARTINEZ-VILLAFAÑE**
}

Universidad Autonoma del Estado de Morelos, CIICAP, Av. Universidad 1001, 62209-Cuernavaca, Mor.,Mexico

*Universidad Autonoma del Estado de Morelos, Facultad de Ciencias Biologicas, Av. Universidad 1001, 62209-Cuernavaca, Mor., Mexico

**Centro de Investigaciones en Materiales Avanzados, Miguel Cervantes 120, Chihuahua, Mexico

Corresponding Author: E-mail: ggonzalez@uaem.mx Tel/Fax (777) 3297084

Received: March 23, 2012; Revised: May 2, 2012; Published: June 18, 2012

\begin{abstract}
Buddleia perfoliata leaves extract has been investigated as a carbon steel corrosion inhibitor in $0.5 \mathrm{M}$ sulfuric acid by using polarization curves, electrochemical impedance spectroscopy and weight-loss tests at different concentrations $(0,100,200,300,400$ and $500 \mathrm{ppm}$ ) and temperatures, namely 25,40 and $60^{\circ} \mathrm{C}$. Results showthat inhibition efficiency increases as the inhibitor concentration increases, decreases with temperature, and reaches a maximum value after $12 \mathrm{~h}$ of exposure, decreasing with a further increase in the exposure time. It was found that the inhibitory effect is due to the presence of tannines on this extract.
\end{abstract}

\section{Keywords}

Corrosion inhibitor, Buddleia perfoliata, EIS, polarization curves.

\section{Introduction}

Due to currently imposed requeriments for eco-friendly corrosion inhibitors, there is a growing interest in the use of natural products such as leaves or seeds extracts. Some papers have reported the use of natural products for mild steel corrosion inhibition in different environments [1-23]. This is due to the fact that sinthetic inhibitors are, among other factors, expensive and highly toxic. Among the so-called "green inhibitors" there are organic compounds, such as ascorbic acid, succinic acid, tryptamine, caffeine, etc., that act by adsorption on metal surface. Additionally, some other natural products such as black pepper, Azadirachta indica, Gossipium hirsutum, 
guanadine, Occimum viridis, Talferia occidentalis and Hibiscus sabdariffa, were used. For instance, Oguzie carried out the inhibitive action of leaf extracts of Sansevieria trifasciata on aluminium corrosion in $2 \mathrm{M} \mathrm{HCl}$ and $2 \mathrm{M} \mathrm{KOH}$ solutions by using the gasometric technique [20]. Results indicated that the extract functioned as a good inhibitor in both environments and inhibition efficiency increased with the increase of the inhibitor concentration. A mechanism of physical adsorption is proposed for the inhibition behaviour. The adsorption characteristics of the inhibitor were approximated by Freundlich isotherm. In another work by Chauhan et al. [3] the inhibition effect of Zenthoxylum alatum plant extract on the corrosion of mild steel in $5 \%$ and $15 \%$ aqueous hydrochloric acid solution has been investigated by weight-loss method and electrochemical impedance spectroscopy (EIS). The corrosion inhibition efficiency increased by increasing the plant extract concentration till $2400 \mathrm{ppm}$. The adsorption of this plant extract on the mild steel surface obeys the Langmuir adsorption isotherm. Okafor et. al. [4] studied the inhibitive action of leaves, seeds and a combination of leaves and seeds extracts of Phyllanthus amarus on mild steel corrosion in $\mathrm{HCl}$ and $\mathrm{H}_{2} \mathrm{SO}_{4}$ solutions using weight- loss and gasometric techniques. The results indicate that the extracts functioned as a good inhibitor in both environments, and inhibition efficiency increases with extracts concentration. The adsorption characteristics of the inhibitor were approximated by Temkin isotherm. The corrosion efficiency of these extracts is normally ascribed to the presenceof complex organic species such as tannins, alkaloids and nitrogen bases, carbohydrates and proteins as well as their acid hydrolysis products.

The genus Buddleia, included in the family Loganiaceae, and previously classified in a family of its own, the Buddlejaceae, is now classified in the family Scrophulariaceae. Native to Asis, Africa, North and South America, Buddleia is a genus containing 100 species, 50 being distributed in America, of which 16 grow in Mexico [22]. Buddleia species are widespread and share some remarkable similarities in their medicinal uses. This may well indicate the presence of the same or similar compounds with a particular pharmacological action. A patterns is emerging about the composition of these compounds; flavonoid and iridoid glycosids being the major seccondary metabolites that have been isolated to date [23]. Buddleia perfoliata became officialy recognized in the 1930 Mexican Pharmacopoeia where it was shown to have antisudorific activity [24]. This plant also contains essential oil, tannic, gallic and oxalic acids [25]. In folk medicines, it is used in the treatment for tuberculosis as well as for catarrh, ptyalism and headaches [25]. In the present paper, we evaluated the inhibitory effect of Buddleia perfoliata in the corrosion of 1018 carbon steel in $0.5 \mathrm{M} \mathrm{H}_{2} \mathrm{SO}_{4}$ by using both gravimetric and electrochemical techniques.

\section{Experimental procedure}

Corrosion tests were performed on coupons prepared from 1018 carbon steel rods containg $0.14 \% \mathrm{C}, 0.90 \% \mathrm{Mn}, 0.30 \% \mathrm{~S}, 0.030 \% \mathrm{P}$ and as balance $\mathrm{Fe}$, encapsulated in commercial epoxic resin with the exposed area of $1.0 \mathrm{~cm}^{2}$. The aggressive solution, $0.5 \mathrm{M} \mathrm{H}_{2} \mathrm{SO}_{4}$ was prepared by dilution of analytical grade $\mathrm{H}_{2} \mathrm{SO}_{4}$ with double distilled water. Dried Buddleia perfoliata leaves (38.7 g) were soaked in $300 \mathrm{ml}$ of methanol during $24 \mathrm{~h}$ and refluxed during $5 \mathrm{~h}$ obtaining a solid, which was weighted and dissolved in methanol untill this was completely evaporated and used as a stock solution and then for preparation of the desired concentrations by dilution. Methanol is commonly used in the obtaining green inhibitors [2-11] and since it completely evaporates, there is no risk of toxicity. Weight-loss experiments were carried out with steel rods of $2.5 \mathrm{~cm}$ in length and $0.6 \mathrm{~cm}$ diameter abraded with fine 1200 grade emery paper, rinsed with acetone, and exposed to the aggressive solution during $72 \mathrm{~h}$. After a total exposition time of $72 \mathrm{~h}$, specimens 
were taken out, washed with distilled water, degreased with acetone, dried and weighed accurately. Specimens were hanging by nylon fibers which were introduced through a hole of 0.5 $\mathrm{mm}$ in diameter, drilled in one end of the specimen. Tests were performed by triplicate at room temperature $\left(25^{\circ} \mathrm{C}\right), 40$ and $60^{\circ} \mathrm{C}$ by using a hot plate. Corrosion rates, in terms of weight loss measurements, $\Delta W$, were calculated as follows:

$$
\Delta W=\left(m_{1}-m_{2}\right) / A
$$

were $m_{1}$ is the mass of the specimen before corrosion, $m_{2}$ the mass of the specimen after corrosion, and $A$ the exposed area of the specimen. For the weight loss tests, inhibitor efficiency, $I E$, was calculated as follows:

$$
I E=100\left(\Delta W_{1}-\Delta W_{2}\right) / \Delta W_{1}
$$

where $\Delta W_{1}$ is the weight loss without inhibitor, and $\Delta W_{2}$ the weight loss with inhibitor. Specimens were removed, rinsed in water and in acetone, dried in warm air and stored in desiccators. Specimens were weighed in an analytical balance with a precision of $0.1 \mathrm{mg}$. Surface analysis of corroded specimens was carried out by a Scanning Electronic Microscope (SEM). Electrochemical techniques employed included potentiodynamic polarization curves and electrochemical impedance spectroscopy (EIS) measurements. In all the experiments, carbon steel electrode was allowed to reach stable open circuit potential value, $E_{\text {corr }}$. Each polarization curve was recorded three times at constant sweep rate of $1 \mathrm{mV} \mathrm{s}^{-1}$ at the interval from -1000 to $+1500 \mathrm{mV}$ in respect to the $E_{\text {corr }}$ value. Measurements were obtained by using a conventional three electrodes glass cell with two graphite electrodes symmetrically situated, and a saturated calomel electrode (SCE) as a reference electrode with a Lugging capillary bridge. Corrosion current density values, $i_{\text {corr }}$, were obtained by using Tafel extrapolation. Inhibitor efficiency, $I E$, was calculated as follows:

$$
I E=100\left(i_{\text {corr } 1}-i_{\text {corr } 2}\right) / i_{\text {corr1 }}
$$

where $i_{\text {corr1 }}$ is the corrosion current density value without inhibitor, and $i_{\text {corr2 }}$ the corrosion current density value with inhibitor. EIS tests were carried out three times at $E_{\text {corr }}$ by using a signal with amplitude of $10 \mathrm{mV}$ in a frequency interval of $100 \mathrm{mHz}-100 \mathrm{KHz}$. An ACM potentiostat, controlled by a desk top computer was used for the polarization curves, whereas for the EIS measurements, a model PC4 300 Gamry potentiostat was used.

\section{Results and discussion}

The effect of Buddleia perfoliata concentration in the polarization curves at $25{ }^{\circ} \mathrm{C}$ is shown in Fig. 1, whereas electrochemical parameters for these curves are shown in Table 1. It can be seen that steel exhibits an active-passive behavior with and without inhibitor; in the uninhibited solution, the steel shows an increase in the anodic current density, but around $400 \mathrm{mV}$ a region where the current remains more or less stable, similar to a passive region, apperas although very unstable since some anodic transients can be seen due to the brakedown and repair of this incipient passive layer. This unstable region dissappears with the addition of 100, 200 or 300 ppm of Buddleia perfoliata and the passive zone becomes stable, but with a further increase of the inhibitor concentration this unstable regions apperas once again. It is clear that the addition of Buddleia perfoliata has caused a clear decrease in both the anodic and cathodic branch of the polarization curves, and this effect is more pronounced as the inhibitor concentration increases; from Table 1 it can be seen that as soon as the extract is added to the electrolyte, the $E_{\text {corr }}$ value 
becomes more negative and the $i_{\text {corr }}$ value decreases, reaching its lowest value when $500 \mathrm{ppm}$ of inhibitor is added.

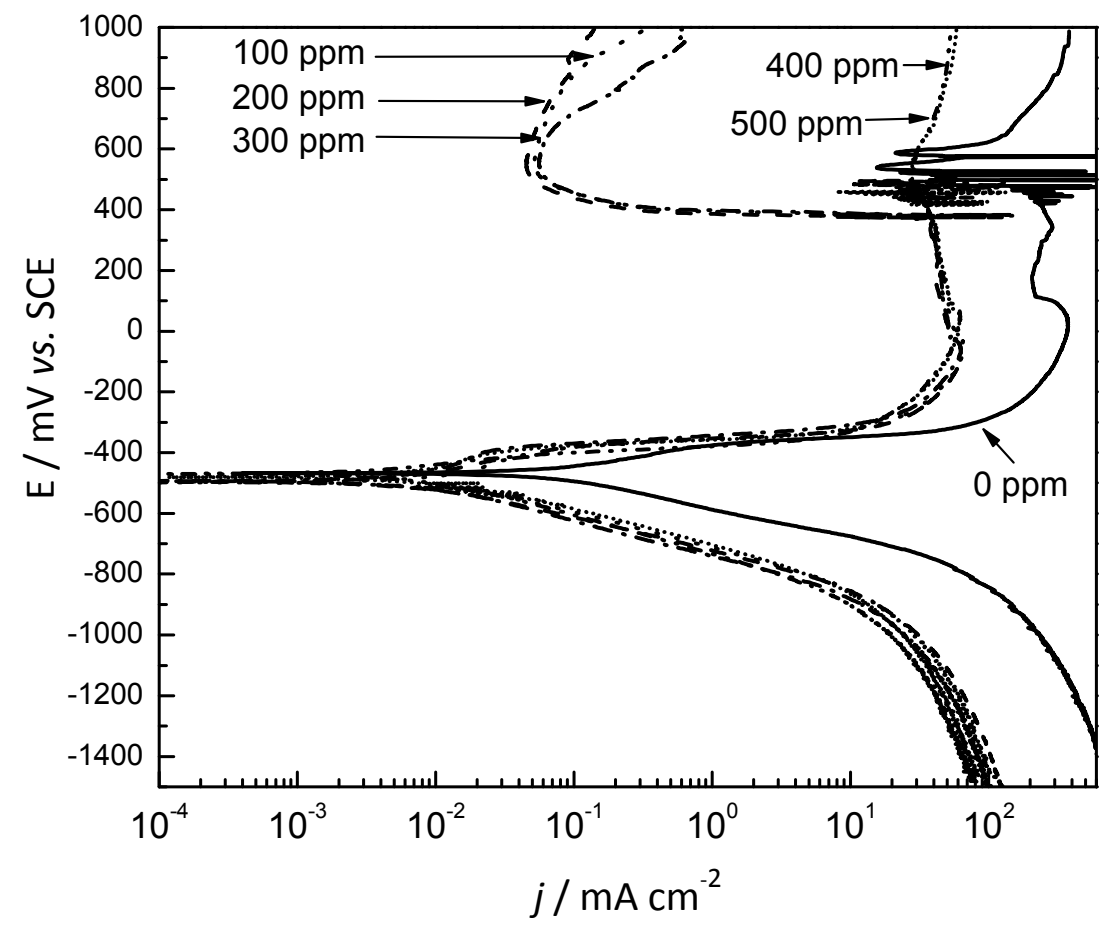

Figure 1. Effect of Buddleia perfoliata concentration in the polarization curves for 1018 carbon steel corroded in $0.5 \mathrm{M} \mathrm{H}_{2} \mathrm{SO}_{4}$ at $25{ }^{\circ} \mathrm{C}$

Table 1. Electrochemical parameters obtained from polarization curves at $25{ }^{\circ} \mathrm{C}$. Estimated error in potential is $\pm 6 \mathrm{mV}$, in current density is $\pm 5 \times 10^{-3} \mathrm{~mA} \mathrm{~cm}^{-2}$ and in resistance is $\pm 1 \times 10^{-3} \Omega \mathrm{cm}^{2}$.

\begin{tabular}{|c|c|c|c|c|c|c|}
\hline $\begin{array}{c}c_{\text {inh }} \\
\text { ppm }\end{array}$ & $\begin{array}{c}E_{\text {corr }} \\
\mathrm{mV} \text { vs. SCE }\end{array}$ & $\begin{array}{c}i_{\text {corr }} \\
\mathrm{mA} \mathrm{cm}^{-2}\end{array}$ & $\underset{\mathrm{mA} \mathrm{cm}^{-2}}{i_{\text {pas }}}$ & $\begin{array}{c}\beta_{\mathrm{a}} \\
\mathrm{mV} \operatorname{dec}^{-1}\end{array}$ & $\begin{array}{c}\beta_{\mathrm{c}} \\
\mathrm{mV} \operatorname{dec}^{-1}\end{array}$ & $\begin{array}{c}R_{\mathrm{p}} \\
\Omega \mathrm{cm}^{2}\end{array}$ \\
\hline 0 & -473 & 0.09 & 50 & 125 & -120 & 60 \\
\hline 100 & -503 & 0.07 & 0.06 & 118 & -115 & 102 \\
\hline 200 & -497 & 0.07 & 0.05 & 108 & -115 & 145 \\
\hline 300 & -491 & 0.06 & 0.04 & 65 & -110 & 240 \\
\hline 400 & -460 & 0.05 & 25 & 60 & -105 & 565 \\
\hline 500 & -478 & 0.05 & 27 & 50 & -105 & 600 \\
\hline
\end{tabular}

As expected, the polarization resistance value, $R_{\mathrm{p}}$, increases as the inhibitor concentration increases, reaching a maximum value when 500 ppm of inhibitor is added. In addition to this, passive current density decreases as the Buddleia perfoliata concentration increases up to 300 ppm, but increasing again with a further increase of the inhibitor concentration. The cathodic slope was practically unaffected by the addition of the Buddleia perfoliata, which indicates that hydrogen evolution reaction is diminished exclusively by the surface blocking effect of adsorbed inhibitor [15]. Regarding the anodic region of the potentiodynamic polarization curves, there is clearly an active-passive behavior either in presence or in absence of the inhibitor. Also, the currents remains almost the same in all cases in the active dissolution region of the metal, but it decreased in the passive region when the inhibitor is added. This behavior could be related to a change in the anodic reaction mechanism (iron dissolution) which is corroborated by a decrease in the anodic Tafel slope with increasing concentration of Buddleia perfoliata [15]. 
Nyquist and Bode diagrams for 1018 carbon steel exposed to $0.5 \mathrm{M} \mathrm{H}_{2} \mathrm{SO}_{4}$ with different Buddleia perfoliata dosis is shown in Fig. 2. Nyquist diagram, Fig. 2a, shows a single deppressed, capacitive semicircle with its center in the real axis regardless of the inhibitor concentration, indicating that the corrosion process is under charge transfer control from the metal to the electrolyte through the electrochemical double layer. This type of plot is characteristic of solid electrodes and it is often ascribed to dispersion effects, which are attributed to roughness and inhomogeneities of the surface during corrosion $[24,25]$.
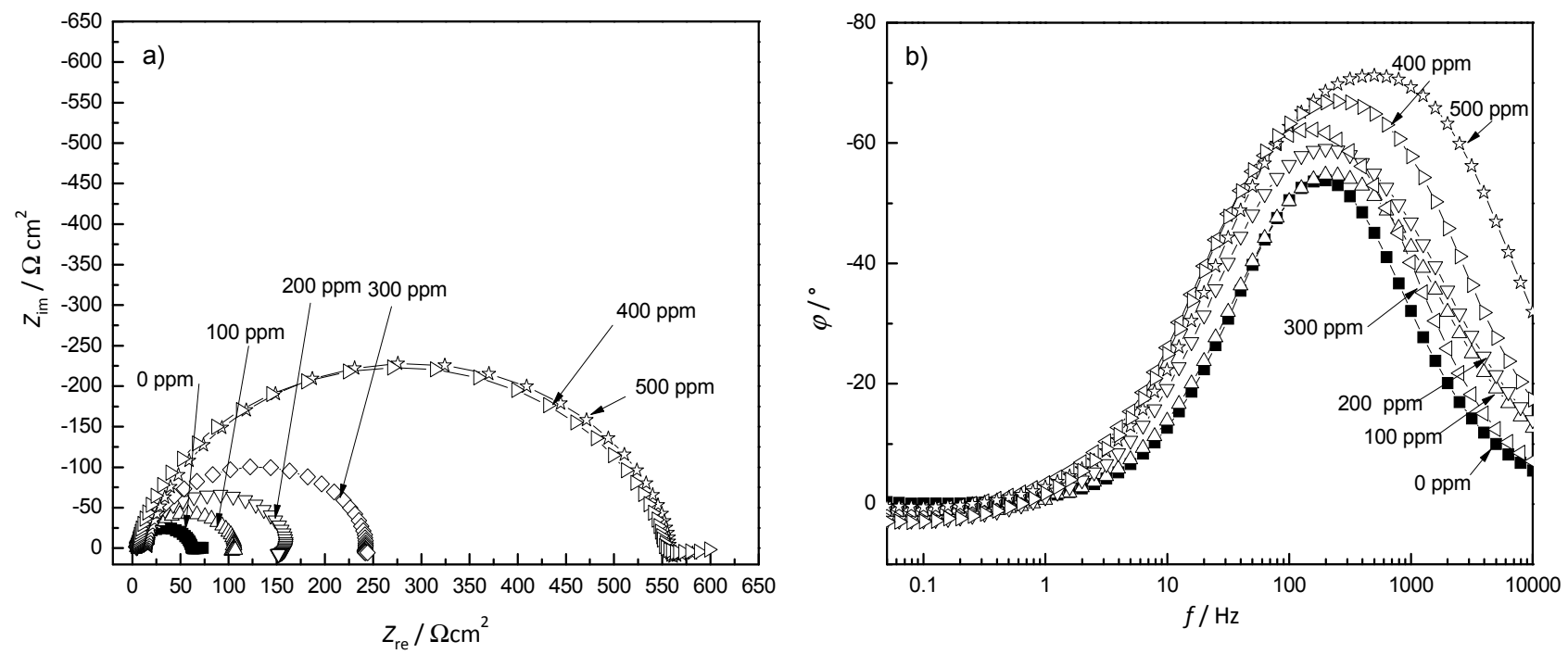

Figure 2. Effect of Buddleia perfoliata concentration in the a) Nyquist and b) Bode diagrams for 1018 carbon steel corroded in $0.5 \mathrm{M} \mathrm{H}_{2} \mathrm{SO}_{4}$ at $25{ }^{\circ} \mathrm{C}$

This behavior is not affected by the presence of the inhibitor, indicating the activationcontrolled nature of the reaction; the semicircle diameter increases with the inhibitor concentration, reaching a maximum value with $500 \mathrm{ppm}$ of inhibitor. These results support those obtained from the polarization curves and confirm the inhibitor adsorption onto carbon steel surface. The intersection of of the semicircle with the real axis at high frequencies provides a value of the solution resistance of $4.3 \Omega \mathrm{cm}^{2}$. The semircle diameter is related to the charge transfer resistance, $R_{\mathrm{ct}}$, inversely proportional to the $i_{\text {corr }}$ value, thus, the lowest corrosion rate is attained with 500 ppm, as indicated by the polarization curves in Fig. 1 and Table 1. For the uninhibited solution, an $R_{\mathrm{ct}}$ value of $52 \Omega \mathrm{cm}^{2}$ was found. Bode diagram, Fig. $2 \mathrm{~b}$, shows a single peak around $200 \mathrm{~Hz}$, which shifts towards higher frequency values as the inhibitor concentration increases up to 500 ppm.

Equivalent electric circuit used to simulate the EIS data for 1018 carbon steel exposed to $0.5 \mathrm{M} \mathrm{H}_{2} \mathrm{SO}_{4}$ with different Buddleia perfoliata dosis is shown in Fig. 3. In Fig. 3, $R_{\mathrm{s}}$ represents the solution resistance, $R_{\mathrm{ct}}$ the charge transfer resistance or the resistance to the flow of electrons from the metal to the electrolyte, and $C_{\mathrm{dl}}$ the capacitance of the electrochemical double layer, or the capacity to storage charge in this layer. However, one has to account for the inhomogeneity of the surface-electrolyte system. When a non-ideal frequency response is present, it is commonly accepted to employ distributed circuit elements in an equivalent circuit. The most widely used is a constant phase element (CPE) or time constant, which has a non-integer power dependence on the frequency. Often a CPE is used in a model in place of a capacitor to compensate for nonhomogeneity in the system. Since only a single peak exists in Bode diagram, Fig. $2 b$, only one time constant is needed to simulate the EIS data. Table 3 summarizes the calculated parameters to simulate the EIS data using circuit shown in Fig. 3 . It can be seen that the $R_{\text {ct }}$ value reaches its 
highest value between 400 and 500 ppm, whereas the electrochemical double layer capacitance, $C_{\mathrm{dl}}$, attains its lowest value at these inhibitor concentrations, which may be attributed to the adsorption of the components in the Buddleia perfoliata extract onto the metal/electrolyte interface or to an increase of the double layer [12].

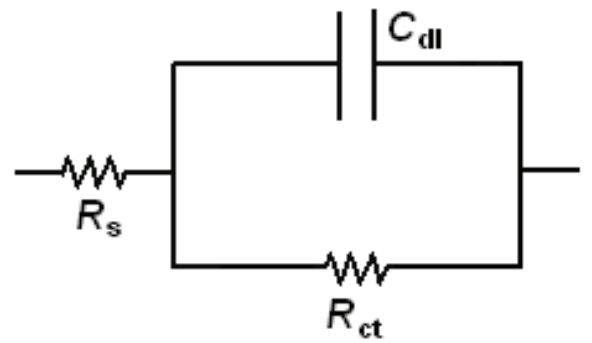

Figure 3. Electric circuit used to simulate the EIS data

Table 3. Calculated parameter values used to simulate the impedance data for EIS data Estimated error in resistance is $\pm 1 \times 10^{-3} \Omega \mathrm{cm}^{2}$ whereas for capacitance it is $\pm 1 \times 10^{-8} \mathrm{~F} \mathrm{~cm}^{-2}$

\begin{tabular}{cccc}
\hline$c_{\text {inh }} / \mathbf{p p m}$ & $\boldsymbol{R}_{\mathrm{s}} / \Omega \mathrm{cm}^{2}$ & $\boldsymbol{R}_{\mathrm{ct}} / \Omega \mathrm{cm}^{2}$ & $\boldsymbol{C}_{\mathrm{dl}} / \mathbf{F ~ c m}^{-2}$ \\
\hline 0 & 4.9 & 52 & $5.3 \times 10^{-5}$ \\
\hline 100 & 6.9 & 102 & $7.8 \times 10^{-6}$ \\
\hline 200 & 5.2 & 145 & $5.3 \times 10^{-6}$ \\
\hline 300 & 4.9 & 240 & $4.1 \times 10^{-6}$ \\
\hline 400 & 4.4 & 565 & $1.7 \times 10^{-6}$ \\
\hline 500 & 4.2 & 600 & $4.7 \times 10^{-7}$ \\
\hline
\end{tabular}

Alternatively, the double layer capacitance, $C_{\mathrm{dl}}$, was calculated from the equation bellow:

$C_{\mathrm{dl}}=1 / 2 \pi f_{\max } R_{\mathrm{ct}}$

where $f_{\max }$ is the frequency value at which the imaginary component of the impedance is maximal. For the uninhibited solution, a $C_{\mathrm{dl}}$ value of $530 \mu \mathrm{F} \mathrm{cm}$-2 was found. Table 3 gives the results for the $R_{\mathrm{s}}, R_{\mathrm{ct}}$ and $C_{\mathrm{dl}}$ values for the solution with and without inhibitor. It is important to note that theincrease of the inhibitor concentration brings an increase in the charge transfer resistance value and a decrease in the double layer capacitance. The decrease in the $C_{d l}$ value can be interpreted as due to the adsorption of the inhibitor onto the electrode surface [22]. The double layer formed at the metal-solution interface is considered as an electric capacitor, whose capacitance decreases due to the displacement of water molecules and other ions originally adsorbed on the electrode by the inhibitor molecules, forming a protective film. The thickness of the film formed increases with increasing concentration of the inhibitor, since more inhibitor adsorbs on the surface, resulting in lower $C_{\mathrm{dl}}$ values.

The stability of any film formed by the inhibitor was evaluated by plotting the Nyquist diagram at different times during $24 \mathrm{~h}$, as shown in Fig. 4. This figure shows that the semicircle diameter remains more or less constant during $8 \mathrm{~h}$, and after this time, the semicircle diameter decreases continuously as time elapses. The change in the $R_{\mathrm{ct}}$ and $C_{\mathrm{dl}}$ values calculated from this figure are shown in Fig. 5, where it is evident that the $R_{\mathrm{ct}}$ values remains more or less constant during the first $8 \mathrm{~h}$, but after this, its value starts to decrease, indicating that the inhibitor remains more or less stable on the steel surface during this time. The $C_{\mathrm{dl}}$ value increases as time elapses, indicating a decrease in the inhibitor film thickness. 


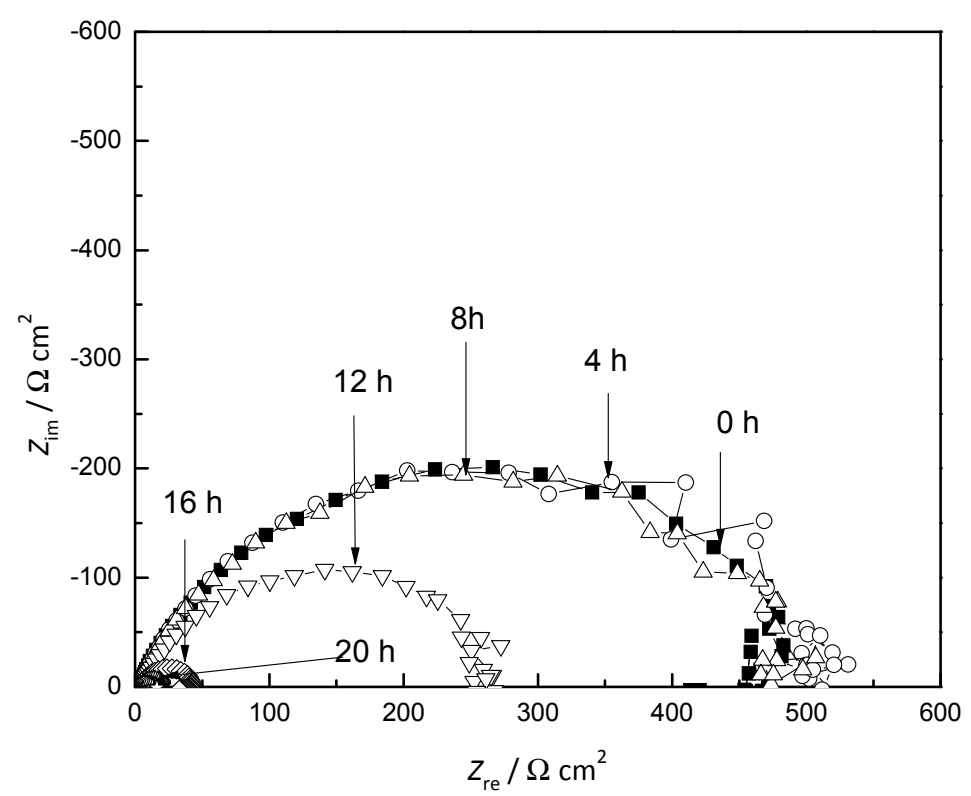

Figure 4. Change of the Nyquist diagram with time for 1018 carbon steel corroded in $0.5 \mathrm{M} \mathrm{H}_{2} \mathrm{SO}_{4}$ at $25{ }^{\circ} \mathrm{C}$ with the addition of $500 \mathrm{ppm}$ of Buddlia perfoliata

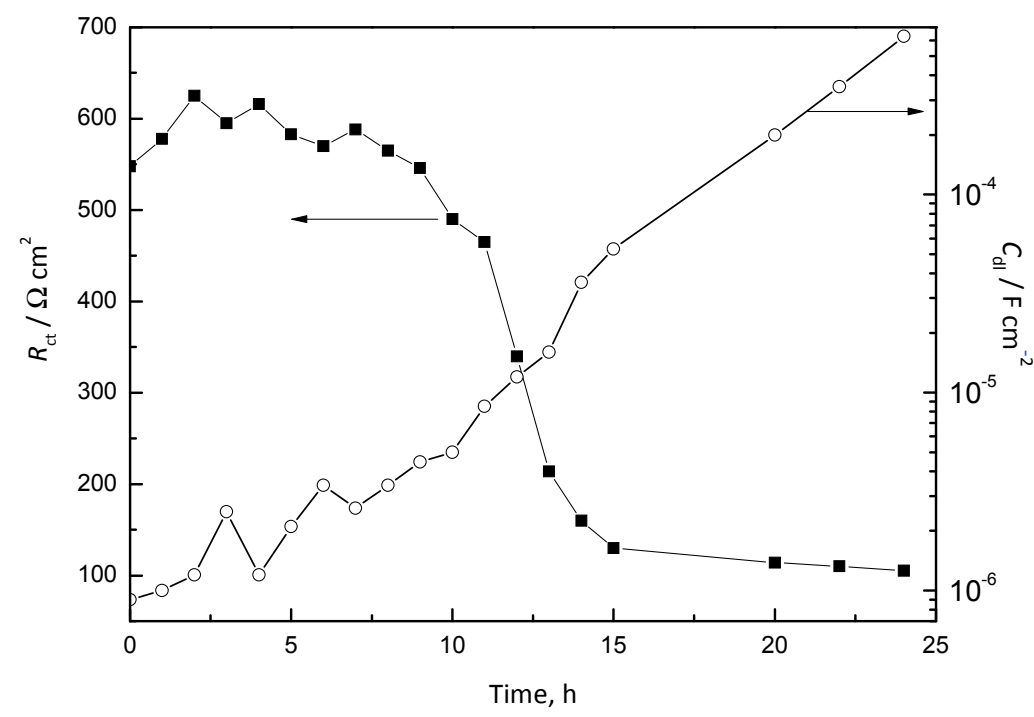

Figure 5. Change of the charge transfer resistance, $R_{c t}$ and double layer capacitance values, $C_{d l}$, with time for 1018 carbon steel corroded in $0.5 \mathrm{M} \mathrm{H}_{2} \mathrm{SO}_{4}$ at $25{ }^{\circ} \mathrm{C}$ with the addition of $500 \mathrm{ppm}$ of Buddleia perfoliata

The $R_{\mathrm{ct}}$ values were used to calculate the IE according to the equation:

$$
I E=100\left(R_{\mathrm{ct} 2}-R_{\mathrm{ct} 1}\right) / R_{\mathrm{ct} 2}
$$

where $R_{\mathrm{ct} 1}$ and $R_{\mathrm{ct} 2}$ are the charge transfer resistance values for the uninhibited and inhibited solution, respectively. The results, together with those obtained by polarization curves (Tafel method), weight-loss and polarization resistance measurements are given in Table 2. It can be clearly seen that all different techniques show that the corrosion inhibition efficiency increases with the increase of inhibitor concentration, reaching a maximum value at $500 \mathrm{ppm}$ of inhibitor. The discrepancy in the IE values obtained from different techniques can be interpreted as the result of different measurements time. Therefore, these results suggest, once again, the formation of an insoluble inhibitor film due to the adsorption of inhibitor onto carbon steel surface. 
Table 2. Efficiency of Buddleia perfoliata as an inhibitor of 1018 carbon steel in $0.5 \mathrm{M} \mathrm{H}_{2} \mathrm{SO}_{4}$ calculated with different techniques. Estimated error in efficieny values is $\pm 3 \%$.

\begin{tabular}{ccccc}
\hline$c_{\text {inh }} / \mathbf{p p m}$ & $\begin{array}{c}\mathrm{IE}_{\text {Tafel slope }}, \\
\%\end{array}$ & $\begin{array}{c}\mathrm{IE}_{\text {Weight-loss }}, \\
\%\end{array}$ & $\begin{array}{c}\mathrm{IE}_{\mathrm{EIS}}, \\
\%\end{array}$ & $\begin{array}{c}\mathbf{I E}_{\text {Pol. resistance }} \\
\%\end{array}$ \\
\hline 100 & 22 & 10 & 47 & 41 \\
\hline 200 & 22 & 15 & 65 & 58 \\
\hline 300 & 33 & 18 & 75 & 69 \\
\hline 400 & 44 & 22 & 84 & 80 \\
\hline 500 & 44 & 27 & 88 & 84 \\
\hline
\end{tabular}

In order to evaluate the adsorption process of Buddleia perfoliata on the 1018 carbon steel surface, Langmuir, Temkin and Frumkin adsorption isotherms were obtained according to the following equations:

Langmuir: $\theta / 1-\theta=K c_{\text {inh }}$

Temkin: $\quad \log \left(\theta / c_{\text {inh }}\right)=\log K-g \theta$

Frumkin: $\quad \log \left(\theta c_{\text {inh }}\right) /(1-\theta)=\log K+g \theta$

where $\theta$ is the surface coverage, $K$ is the adsorption-desorption equilibrium constant, $c_{\text {inh }}$ is the inhibitor concentration and $g$ is the adsorbate interaction parameter. The three isotherms tested fitted well the data obtained, as can be seen in the Fig. 6 indicating that Buddleia perfoliata is adsorbed onto the carbon steel surface. However, the isotherm which gave the best $R^{2}$ value, 0.996, was the Frumkin one. From the Frumkin isotherm, the adsorption-desorption equilibrium constant $\mathrm{K}$ was determined as $3.785 \mathrm{~L} \mathrm{mg}^{-1}$ leading to an adsorption free-energy value of $-37.4 \mathrm{~kJ}$ $\mathrm{mol}^{-1}$. Generally, values of the adsorption free-energy much less than $-40 \mathrm{~kJ} \mathrm{~mol}^{-1}$ have typically been correlated with the electrostatic interactions between organic molecules and charged metal surface (physisorption) whilst those values in the order of $-40 \mathrm{~kJ} \mathrm{~mol}^{-1}$ are associated with charge sharing, or charge transfer from the organic molecules to the metal surface (chemisorption) to form a co-ordinate type of bond [26].The negative value of the free-energy of adsorption value means that the adsorption process is spontaneous, while the value around $-40 \mathrm{~kJ} \mathrm{~mol}^{-1}$ indicates that Buddleia perfoliata was chemisorbed on steel surface. The Temkin isotherm, Fig. $5 \mathrm{~b}$, also shows a good correlation with the experimental data, and the negative value of the slope indicates the existance of a repulsive lateral interaction in the adsorption layer [26].

The effect of temperature on the corrosion of carbon steel in the uninhibited and inhibited $0.5 \mathrm{M} \mathrm{H}_{2} \mathrm{SO}_{4}$ solutions was studied using both, potentiodynamic polarization curves and EIS tests. Fig. 7 shows the effect of temperature on the polarization curves for uninhibited and inhibited solution containing $500 \mathrm{ppm}$ of inhibitor, respectively. It was found that the corrosion rate of steel in both, uninhibited and inhibited, solutions increases as the temperature increases. However, the extent of the rate increment in the inhibited solution is higher in the uninhibited than in the inhibited solution. This suggests that the corrosion inhibition might be caused by the inhibitor adsorption onto the steel surface from the acidic solution, and higher temperatures might cause a stronger adsorption of the inhibitor on the steel surface. 

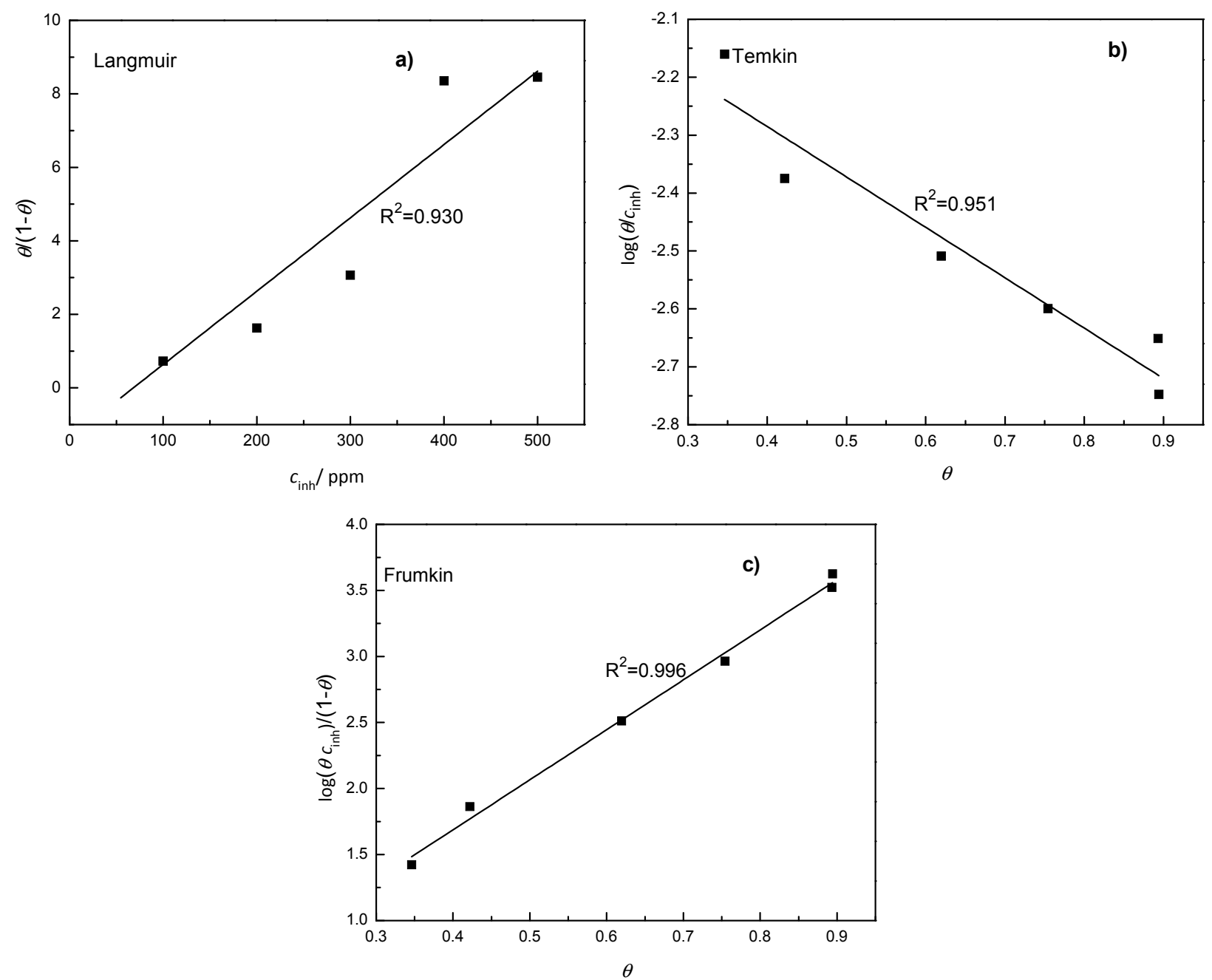

Figure 6. a) Langmuir b) Temkin and c) Frumkin adsorption isotherm for 1018 carbon steel in $0.5 \mathrm{M} \mathrm{H}_{2} \mathrm{SO}_{4}$ at $25{ }^{\circ} \mathrm{C}$ with the addition of Buddleia perfoliata

The apparent activation energy, $E_{\mathrm{a}}$, associated with 1018 carbon steel in uninhibited and inhibited acid solution was determined by using an Arrhenius-type plot according to the following equation:

$$
\log i_{\text {corr }}=-E_{\mathrm{a}} / 2.303 R T+\log F
$$

where $i_{\text {corr }}$ is the corrosion current density value, $R$ is the molar gas constant, $T$ is the absolute temperature and $F$ is the frequency factor. Arrhenius plots of $\log i_{\text {corr }}$ against $T^{1}$ for 1018 carbon steel in $0.5 \mathrm{M} \mathrm{H}_{2} \mathrm{SO}_{4}$ in absence and presence of Buddleia perfoliata are shown in Fig. 8. The apparent activation energy obtained for the corrosion process in the inhibitor-free, uninhibited acid solution was found to be 83.9 , and $63.9 \mathrm{~kJ} \mathrm{~mol}^{-1}$ in the presence of the inhibitor. Notably, the energy barrier of the corrosion reaction decreased in the presence of the inhibitor, which can be due to the chemisorption of the inhibitor on the steel surface. 

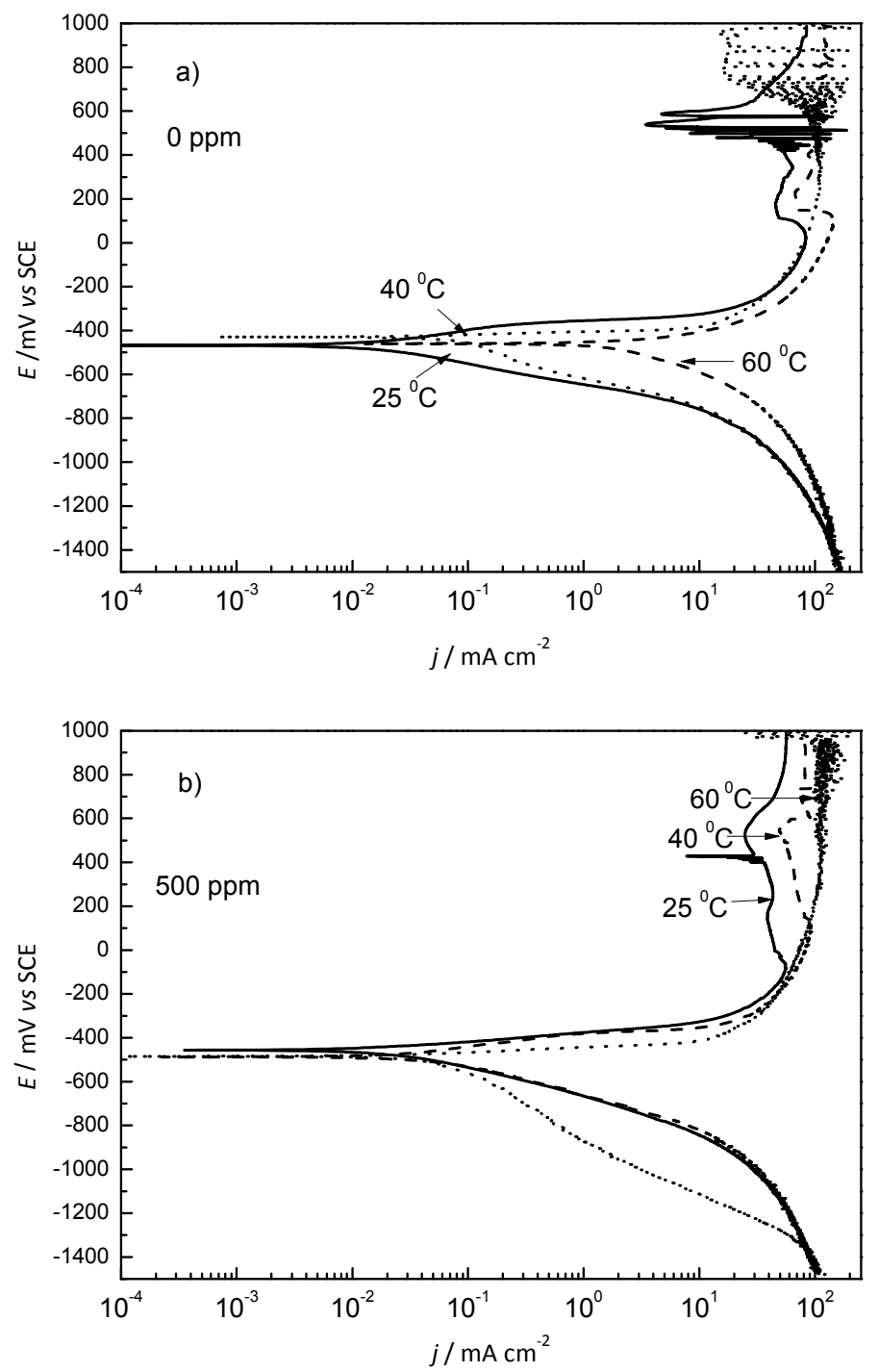

Figure 7. Effect of temperature in the polarization curves for 1018 carbon steel corroded in $0.5 \mathrm{M} \mathrm{H}_{2} \mathrm{SO}_{4}$ a) wihout and b) with 500 ppm of Buddleia perfoliata

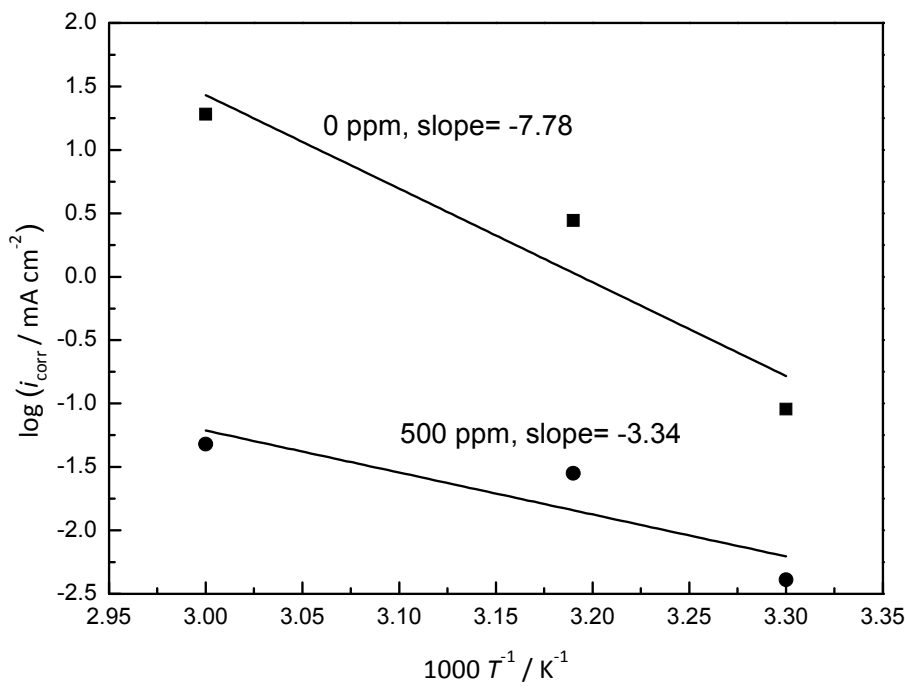

Figure 8. Arrhernius plots for log ( $\mathrm{i}_{\text {corr }}$ ) vs. $1000 \mathrm{~T}^{-1}$ for 1018 carbon steel corroded in $0.5 \mathrm{M} \mathrm{H}_{2} \mathrm{SO}_{4}$ wihout and with 500 ppm of Buddleia perfoliata 
In a way similar to the polarization curves, the effect of temperature on the Nyquist diagrams for uninhibited and inhibited solutions are shown in Figs. 9 and 10, respectively. In both cases it can be seen that the semicircle diameters, and thus, the $R_{\mathrm{ct}}$ values, decreased as the temperature increased, which was more evident for the inhibited solution. An Arrhernius plot of $\log 1 / R_{\mathrm{ct}}$ against $T^{1}$ for 1018 carbon steel in $0.5 \mathrm{M} \mathrm{H}_{2} \mathrm{SO}_{4}$ in absence and presence of Buddleia perfoliata is shown in Fig. 10, where apparent activation energy obtained for the corrosion process in the free acid solution was found to be 4.31 and $3.5 \mathrm{~kJ} \mathrm{~mol}^{-1}$ in presence of the inhibitor.
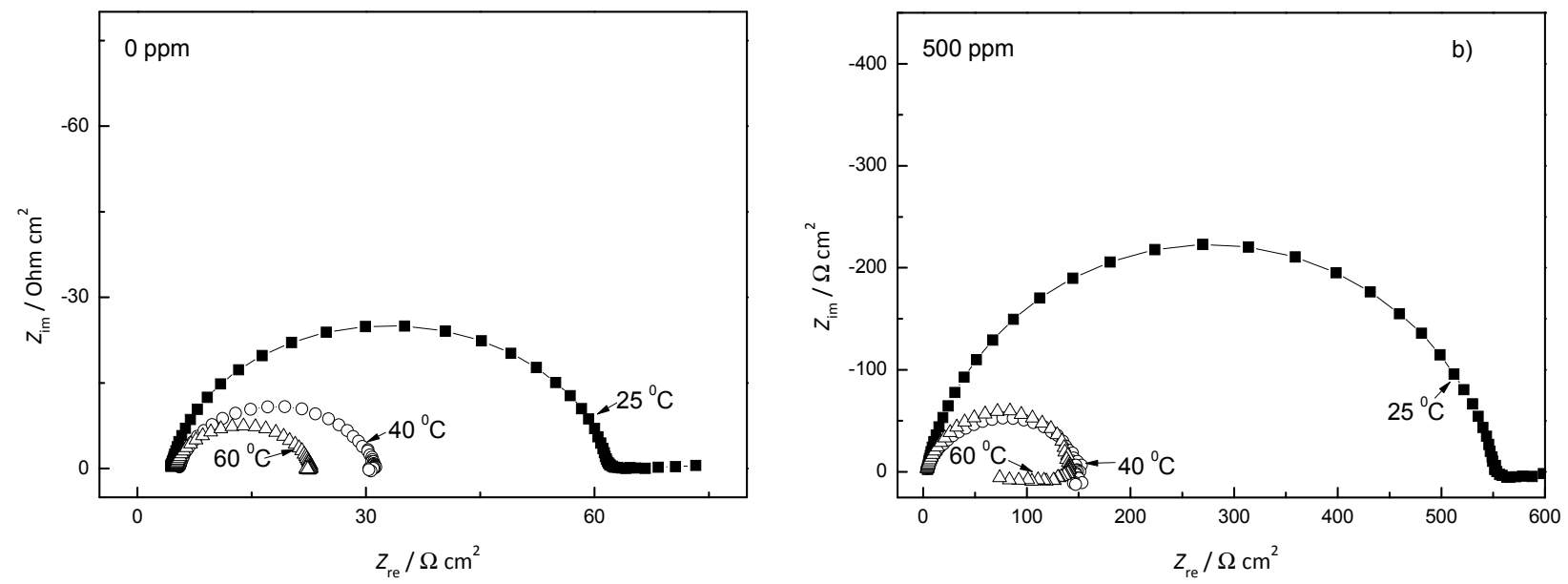

Figure 9. Effect of temperature in the Nyquist diagrams for 1018 carbon steel corroded in $0.5 \mathrm{M} \mathrm{H}_{2} \mathrm{SO}_{4}$ a) wihout and b) with $500 \mathrm{ppm}$ of Buddleia perfoliata

According to Popova et al. [27] lower $E_{\mathrm{a}}$ values in solutions in presence of Buddleia perfoliata indicate a specific type of adsorption of the inhibitor, while Szauer and Brandt [28] associate this behavior with the chemisorption of the inhibitor to the metal surface. Taking into consideration these references and the $E_{\mathrm{a}}$ value calculated from the Arrhenius plots, the action of Buddleia perfoliata as a corrosion inhibitor for 1018 carbon steel in acid solution can be attributed to a strong type of chemisorption of the inhibitor onto metal surface.

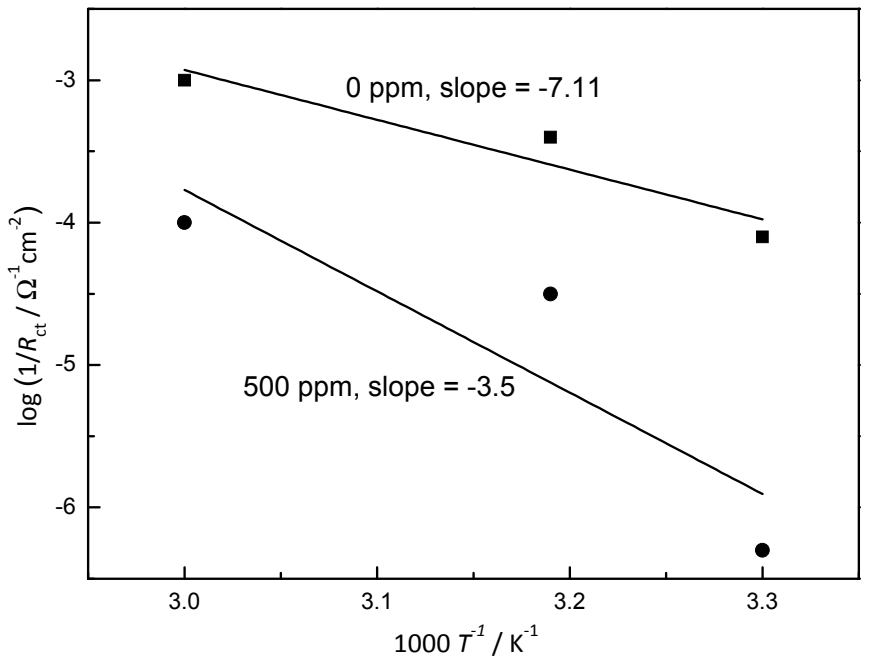

Figure 10. Arrhernius plots for log $\left(1 / \mathrm{R}_{c t}\right)$ vs. $1000 \mathrm{~T}^{-1}$ for 1018 carbon steel corroded in $0.5 \mathrm{M} \mathrm{H}_{2} \mathrm{SO}_{4}$ without and with 500 ppm of Buddleia perfoliata

Some micrographs of 1018 carbon steel specimens, after being exposed to corrosion in $0.5 \mathrm{M}$ $\mathrm{H}_{2} \mathrm{SO}_{4}$, with and without additions of Buddleia perfoliata, are shown in Fig. 11. For the uninhibited solution (Fig. 11 a), only a surface showing uniform corrosion can be seen, but after addition of 
200 ppm of Buddleia perfoliata (Fig. 11 b), a porous, non-protective layer of corrosion products can be seen; however, after addition of 400 ppm of inhibitor (Fig. $11 \mathrm{c}$ ), this layer is much more compact, but it still shows some cracks, indicating that it is not protective enough; finally, at the same inhibitor concentration of $400 \mathrm{ppm}$ but at $60{ }^{\circ} \mathrm{C}$ (Fig. $11 \mathrm{~d}$ ), the layer of corrosion products becomes more porous than the one at $25^{\circ} \mathrm{C}$, and becomes less protective, as indicated by all data.

a

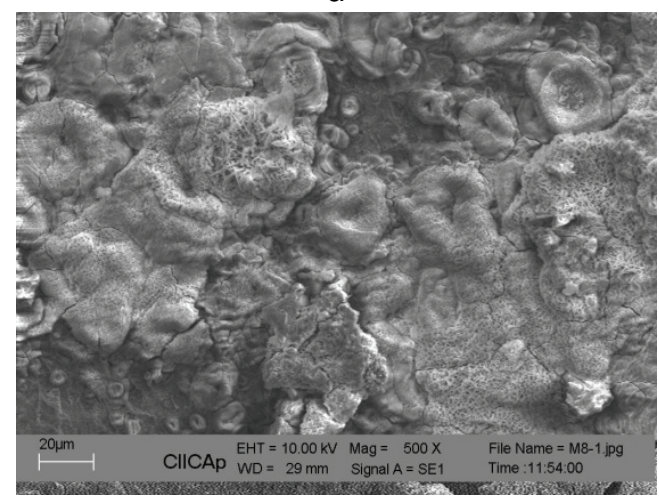

C

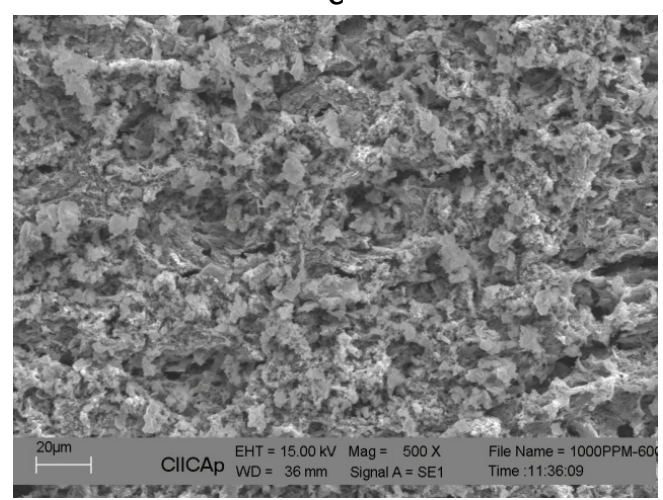

b

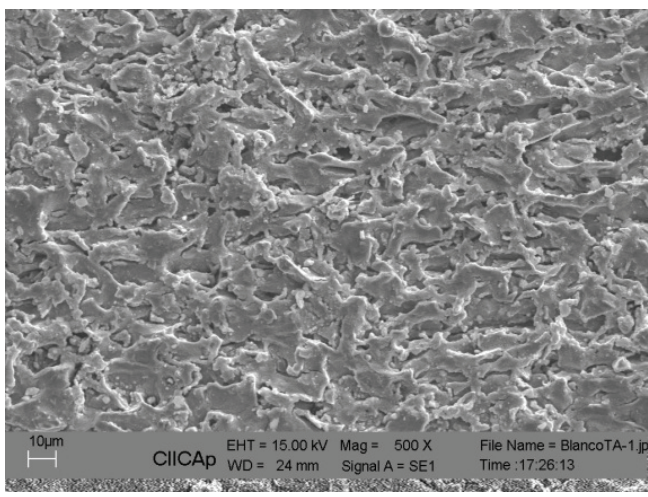

d

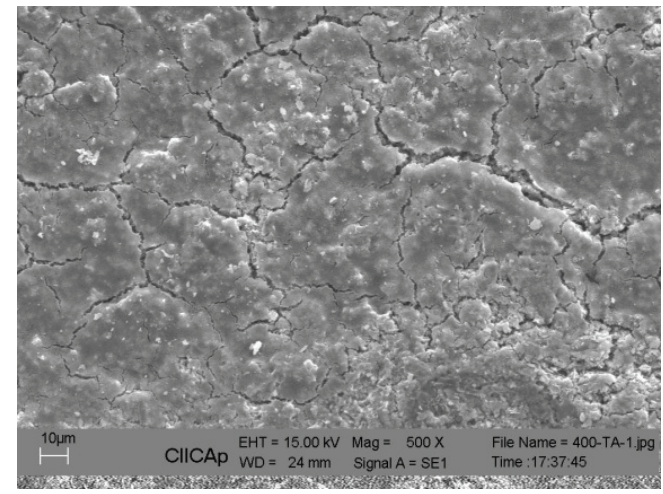

Figure 11. Micrographs of 1018 carbon steel corroded in $0.5 \mathrm{M} \mathrm{H}_{2} \mathrm{SO}_{4}$ with addition of a) 0, b) 200 c) $400 \mathrm{ppm}$ at $25{ }^{\circ} \mathrm{C}$ and d) $400 \mathrm{ppm}$ at $60{ }^{\circ} \mathrm{C}$ of Buddleia perfoliata

The use of Buddleia perfoliata in traditional medicine has been atributed to the presence of some flavonoids as well as some essential oil, tannic, gallic and oxalic acid [23-24]. UV-visible spectra analysis were performed for the acidic solution containing the extract before and after the corrosion test. For the extract before the corrosion test, the UV-spectrum shows an absorption peak at $360 \mathrm{~nm}$ (Fig. 12) corresponding to tannins; after the addition of the extract to the acidic solution, tannins are hydrolyzed producing galic and ellagic acids [25]. Condensed tannins, called pro-antocianidines, are polymers of flavonoids. Formation of a complex formed with $\mathrm{Fe}^{2+}$ ions and $\mathrm{OH}^{-}$groups present in condensed tannins are responsible for the corrosion protection of the metal. As the temperature increases, the degree of polymerization increases and the formed species are more complex and more easily oxidized until the formed corrosion products are detached from the surface and corrosion protection decreases. 


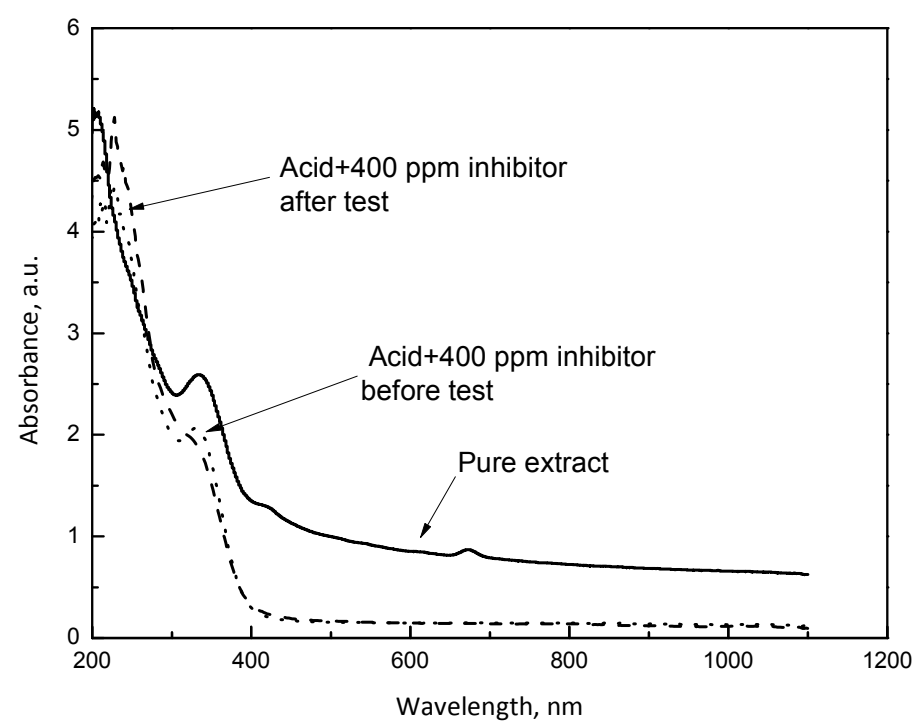

Figure 12.UV visible spectra of pure Buddleia perfoliata extract, $0.5 \mathrm{M} \mathrm{H}_{2} \mathrm{SO}_{4}+400 \mathrm{ppm}$ of inhibitor before and after the corrosion test.

\section{Conclusions}

A study of Buddleia perfoliata leaves extract as corrosion inhibitor for 1018 carbon steel in 0.5 $\mathrm{M} \mathrm{H}_{2} \mathrm{SO}_{4}$ has been investigated by using electrochemical techniques and weight-loss tests. Results have shown that Buddleia perfoliata leaves extract acts as a good inhibitor, and its efficiency increases with increasing the concentration up to $500 \mathrm{ppm}$ but it decreases by increasing the temperature, and remains on the metal surface no more than $12 \mathrm{~h}$. It was found that the inhibitory effect is due to the presence of tannines from this extract which form a protective layer by reacting with $\mathrm{Fe}^{2+}$ ions, and which are chemisorbed onto the metal surface following Frumkin type of adsorption isotherm and the corrosion reaction energy barrier is decreased.

\section{References}

[1] H. Ashassi-Sorkhabi, M. Es'haghi, J. Solid State Electrochem. 13 (2009) 1297-1301

[2] M. Behpour, S. M. Ghoreishi, M. Khayatkashani, N. Soltani, Mater. Chem. Phys. 131 (2012) 621-633

[3] L. R. Chauhan, G. Gunasekaran, Corros. Sci. 49 (2007) 1143-1161

[4] P. C. Okafor, M. E. Ikpi, I. E. Uwah, E. E. Ebenso, U. J. Ekpe, S. A. Umoren, Corros. Sci. 50 (2008) 2310-2317

[5] K. F. Khaled, J. Solid State Electrochem. 11 (2009) 1743-1749

[6] M. Z. A. Rafiquee, S. Khan, N. Saxena, M. A. Quraishi, J. Appl. Electrochem. 39 (2009) 14091417

[7] H. Ashassi-Sorkhabi, E. Asghari, J. Appl. Electrochem. 40 (2009) 631-637

[8] M. A. Quraishi, A. Singh, V. K. Singh, D. K. Yadav, A. K. Singh, Mater. Chem. Phys. 122 (2010) 114-122

[9] A. Y. El-Etre, Mater. Chem. Phys. 108 (2008) 278-282

[10] A. Bouyanzer, B. Hammouti, L. Majidi, Mater. Letters 60 (2006) 2840-2843

[11] G. O. Avwiri, F. O. Igho, Mater. Letters 57 (2003) 3705-3711

[12] I. B. Obot, N. O. Obi-Egbedi, J. Appl. Electrochem. 40 (2010) 1977-1984

[13] K. W. Tan, M. J. Kassimi, Corros. Sci. 53 (2011) 569-574 
[14] P. Lowmunkhong, D. Ungthararak, P. Sutthivaiyakit, Corros. Sci. 52 (2010) 30-36

[15] O. K. Abiola, J. O. E. Otaigbe, O. J. Kio, Corros. Sci. 51 (2009) 1879-1881

[16] K. F. Khaled, Mater. Chem. Phys., 112 (2008) $104-111$

[17] F. S. De Souza, A. Spinelli, Corros. Sci. 51 (2009) 642-649

[18] C. A. Loto, A. P. I. Popola, Int. J. Electrochem. Sci. 6 (2011) 3264-3276

[19] L. Valek, S. Martinez, Mater. Letters 61 (2007) 148-151

[20] E. E. Oguzie, Corros. Sci. 49 (2007) 1527-1539

[21] F. Bentiss, M. Lagrenee, M. Traisnel, Corrosion 56 (2000) 733-742

[22] A. G. Ocampo in "Flora del Bajio y de Regiones Adyacentes" eds. J. Rzedowski, G. Calderon, Mexico, (2003) 1-7

[23] P. J. Houghton, J. Ethnopharm. 11 (1984) 293-308

[24] P. J. Houghton, A.Y. Mensah, N. Lessa, L. Yong-Hong, Photochemistry 64 (2003) 385-393

[25] A. Avila, J. Guillermo, A. Romo de Vivar, Biochem. System. Ecol. 30 (2002) 1003-1005

[26] S. Martinez, I. Stern, Appl. Surf. Sci. 199 (2002) 83-90

[27] A. Popova, E. Sokolova, S. Raicheva, M. Christov, Corros. Sci. 45 (2003) 33-58

[28] T. Szauer, A. Brandt, Electrochim. Acta 26 (1981) 1253-1256

(C) 2012 by the authors; licensee IAPC, Zagreb, Croatia. This article is an open-access article distributed under the terms and conditions of the Creative Commons Attribution license (http://creativecommons.org/licenses/by/3.0/) (cc) Br 